\title{
Compreensão de Conceitos das Ciências Biológicas por Estudantes de uma Escola Pública de Salvador e sua Interface com o Letramento Científico
}

\author{
Comprehension of Concepts of Biology by Students of a Public School in \\ Salvador and its interface with Scientific Literacy
}
Comprensión de los conceptos de ciencias biológicas por parte de estudiantes de una escuela pública en Salvador y su interfaz con la alfabetización científica

\begin{abstract}
Nestor Barbosa de Oliveira-Junior (nestor_barbosa12@ hotmail.com) Universidade Federal da Bahia (UFBA).
\end{abstract}

David Santana Lopes (davidlopes.educacao@gmail.com) Universidade Federal da Bahia (UFBA).

Resumo: O Letramento Científico vem se configurando como um importante campo de pesquisa, não só como indicador, mas também como prática no contexto do Ensino de Ciências. As definições de competências para a formação de um indivíduo cientificamente letrado têm sido adotadas por documentos orientadores como a BNCC, elevando as discussões para os diferentes campos do saber da Ciências da Natureza, como a Biologia, que traz consigo especificidades quando discutidas as complexidades conceituais que a envolvem. Atento a essa teia de relações, este trabalho tem como objetivo investigar as possíveis dimensões de Letramento Científico de estudantes de uma escola pública de Salvador a partir da compreensão de conceitos presentes nas Ciências Biológicas. Como resultado, foi possível observar que os estudantes têm dificuldades na compreensão de termos científicos ligados a Biologia e apresentam discussões que são majoritariamente baseadas em percepções do senso comum e não alicerçados em conceitos científicos.

Palavras-chave: Letramento Científico; Ensino de Biologia; Ensino de Ciências; Base Nacional Comum Curricular; Programa Internacional de Avaliação Alunos.

Abstract: Scientific Literacy is becoming an important research field, not only as an indicator, but also as a practice in the context of Science Teaching. The definitions of competencies for the formation of a scientifically literate individual have been adopted by guiding documents such as the BNCC, elevating the discussions to the different fields of knowledge in the Natural Sciences, such as Biology, which brings with it specificities when discussing the conceptual complexities that involve it. Attentive to this web of relationships, this work aims to investigate the possible dimensions of Scientific Literacy of students from a public school in Salvador from the understanding of concepts present in the Biological Sciences. As a result, it was possible to observe that students have difficulties in understanding scientific terms related to Biology and present discussions that are mostly based on common sense perceptions and not based on scientific concepts.

Recebido em: 02/02/2021

Aceite em: 14/06/2021 
Keywords: Scientific Literacy; Biology teaching; Science teaching; Common National Curriculum Base; International Student Assessment Program.

Resumen: La Alfabetización Científica se ha convertido en un importante campo de investigación, no solo como indicador, sino también como práctica en el contexto de la Educación Científica. Las definiciones de competencias para la formación de un individuo científicamente alfabetizado han sido adoptadas por documentos rectores como el BNCC, elevando las discusiones a los diferentes campos del conocimiento en las Ciencias Naturales, como la Biología, que trae consigo especificidades al discutir los conceptos conceptuales. complejidades que lo involucran. Atento a esta red de relaciones, este trabajo tiene como objetivo investigar las posibles dimensiones de la Alfabetización Científica de los estudiantes de una escuela pública en Salvador a partir de la comprensión de conceptos presentes en las Ciencias Biológicas. Como resultado, fue posible observar que los estudiantes tienen dificultades para comprender términos científicos relacionados con la Biología y presentar discusiones que se basan en su mayoría en percepciones de sentido común y no en conceptos científicos.

Palabras-clave: Alfabetización científica; Enseñanza de la biología; Enseñanza de las ciencias; Base de currículo nacional común; Programa Internacional de Evaluación de los Alumnos.

\section{INTRODUÇÃO}

O Letramento Científico (LC) tornou-se um objeto de investigação recorrente por pesquisadores brasileiros nas últimas décadas, que buscam não só o seu entendimento epistemológico, como sua aplicação nos mais diversos campos do saber (LIMA; WEBER, 2019). No Brasil, o LC é balizado a partir das competências definidas pela Organização para a Cooperação e o Desenvolvimento Econômico (OCDE) no âmbito do Programa Internacional de Avaliação de Alunos (PISA). Em síntese, o LC pode ser caracterizado como a "capacidade de se envolver com questões relacionadas com a ciência e com a ideia da ciência, como cidadão reflexivo" (BRASIL, 2019, p. 118).

Outros documentos orientam também a construção dos objetivos de Letramento Científico no Ensino de Ciências, como a Base Nacional Comum Curricular - BNCC (BRASIL, 2018). Em estudos como o de Branco e Zanatta (2021), os autores ressaltam que a BNCC vem enfatizando o Ensino de Ciências pautado com ênfase no desenvolvimento de habilidades e competências em detrimento dos conteúdos. Contudo, mesmo diante de tais orientações, o documento ainda não apresenta caminhos profícuos para que os objetivos do LC se efetivem.

Recebido em: 02/02/2021

Aceite em: 14/06/2021 
Desta forma, a importância de se discutir sobre o LC no contexto da educação formal é ainda maior, sendo o foco, o ambiente escolar no qual os estudantes têm os primeiros contatos com os conhecimentos científicos sistematizados. São esses conhecimentos científicos que subsidiarão o sujeito durante seu percurso formativo (ARAÚJO; BARROS; BARROS, 2018), para que ele seja capaz de desenvolver discursos e práticas pautadas nas ciências, possibilitando a ampliação da esfera conceitual para a esfera crítica e reflexiva. Mesmo assim, Lorenzetti e Delizoicov (2001) já afirmavam que os estudantes não eram ensinados a como fazer conexões críticas entre os conhecimentos sistematizados pela escola, juntamente com temas cotidianos desde o início da formação.

No que se refere à própria educação formal, o Brasil, segundo os dados técnicos do PISA no ano de 2018, ocupou apenas a $64^{\circ}$ colocação entre 78 países nas avaliações de conhecimento em Ciências, levando como base três indicadores para letramento científico, sendo eles a capacidade de explicar fenômenos cientificamente, avaliar e planejar experimentos científicos e interpretar dados e evidências cientificamente (BRASIL, 2017). Ainda que a avaliação do PISA seja pautada por uma racionalidade técnica, essa situação expõe não apenas as dificuldades de compreensão de conceitos científicos, mas do emprego desses em distintos contextos sociais e formativos.

Outras organizações também se dedicam a analisar os Indicadores de Letramento Científico (ILCs) no Brasil, como o Instituto Brasileiro de Letramento Científico (IBL). Tais instituições se debruçam sobre os indicadores do PISA, atrelado às diferentes dimensões de LC, sendo elas: a) Nominal, b) Funcional, c) Conceitual e d) Multidimensional (INSTITUTO ABRAMUNDO, 2014). De acordo com o IBL, Serrao et al. (2016) apontam que os sujeitos da pesquisa que estão cursando ou já concluíram o Ensino Médio, se comparados aos que apenas concluíram o Ensino Fundamental, 52\% e 50\% respectivamente, encontravam-se nos níveis de LC Rudimentar, interpretando apenas conceitos científicos de baixa complexidade.

No Brasil, o Ensino de Ciências tradicional é fruto de um processo histórico de repetição de fórmulas, definições e classificações (DEL PINO; STRACK, 2012) tornando a abordagem das Ciências da Natureza uma mera formalidade. Este modelo ultrapassado limita os estudantes à mera compreensão dos termos científicos, sem que haja aprofundamento a níveis de (re)significação estendido a outros contextos. 
Essa realidade é discutida por Krasilchik e Marandino (2004, p. 5) que enfatizam a necessidade de um Ensino de Ciências caracterizado pela capacidade de servir ao cidadão para "participar e usufruir das oportunidades, das responsabilidades e dos desafios cotidianos". No entanto, a forma descontextualizada como o Ensino de Ciências é praticado nas escolas faz com que conceitos científicos se transformem em expressões tomadas como meros ornamentos culturais repetidos pelos estudantes, por vezes sem qualquer significação cultural (SANTOS, 2007).

Nesse sentido, Soares (2004, p. 6) destaca a necessidade do [...] "desenvolvimento de comportamentos e habilidades de uso competente da leitura e da escrita em práticas sociais [...] que ultrapassem o domínio do sistema alfabético e ortográfico [...]”. A autora discute a necessidade do rompimento das esferas de um aprendizado meramente alfabético, para outro que propõe a quebra da superficialidade da compreensão apenas a nível conceitual. Mesmo pautada nos pressupostos da alfabetização científica, que é diferenciada por alguns autores do LC, a literatura que orienta este artigo, como a de Soares (2004), compreende a necessidade da leitura e da escrita serem redimensionadas além do seu significado conceitual, inclusive no campo das ciências, dialogando com as concepções apresentadas nesta produção acadêmica.

Imerso nesse contexto, o Ensino de Biologia traz consigo importantes debates acerca da compreensão de termos científicos, definidos como desafiadores por Branco et al. (2018), pois apresentam terminologias e conceitos complexos e, muitas vezes, distantes da realidade do educando. Alguns desses conceitos exigem uma elevada capacidade de abstração e visão holística para além de uma compreensão conceitual.

Essa é uma tarefa difícil também para o professor, como já discutido por Mayer, Leão e Bastos (2001), além de Duré, Andrade e Abílio (2018), pois a Biologia ao apresentar uma diversidade de saberes acerca de uma vasta diversidade de seres vivos, além de mecanismos em sua maioria abstratos, torna-se um desafio para a prática docente. De acordo com Albuquerque, Braga e Gomes (2012, p. 59), por vezes, o formato memorizador de conceitos presente na Biologia faz com que os estudantes passem a "não relacionar o que aprendem com a vida cotidiana [...] ocorre uma simples memorização temporária e no momento em que esses conceitos poderiam ser empregados pelo aluno na vida real, eles já foram esquecidos".

Os pressupostos do LC e os desafios do Ensino de Biologia, em especial a compreensão de seus conceitos e os desafios que o envolvem, pode produzir um rico diálogo. O primeiro 
por representar uma prática cada vez mais presente nas discussões no campo das Ciências, e o segundo por ser construído por especificidades conceituais que envolvem desafios articulados com as particularidades das áreas que compõem as Ciências da Natureza.

Nesse sentido, atento a essa interface, o presente estudo tem como objetivo investigar as possíveis dimensões de Letramento Científico de estudantes de uma escola pública de Salvador a partir da compreensão de conceitos presentes nas Ciências Biológicas. Nos próximos tópicos, serão apresentadas experiências formativas que associam o escopo teórico apresentado com os relatos do corpo discente em torno de práticas que buscaram incentivar o LC em um ambiente formativo.

\section{PERCURSO METODOLÓGICO}

Esta pesquisa de caráter qualitativo e exploratório foi desenvolvida no âmbito do Programa Institucional de Bolsa de Iniciação à Docência, subprojeto Biologia, da Universidade Federal da Bahia (PIBID/CAPES/UFBA), no Colégio Estadual Ministro Aliomar Baleeiro (CEMAB), Salvador, Bahia. A escola abriga séries do Ensino Fundamental e Médio, totalizando cerca de 1,327 estudantes nos três turnos (BAHIA, 2019) e é localizada no Bairro de Pernambués, zona urbana da Cidade de Salvador, com cerca de $80 \%$ dos moradores autodeclarados negros, constituindo a área mais negra do Município.

Participaram como sujeitos da pesquisa 25 estudantes cursando o $3^{\circ}$ ano do Ensino Médio do CEMAB, do turno matutino, com faixa etária entre 17 e 22 anos, de ambos os sexos. Os procedimentos éticos da pesquisa contaram com o preenchimento do Termo de Consentimento Livre e Esclarecido (TCLE) pelos estudantes, além do Termo de Anuência Institucional assinado pela Coordenação Pedagógica.

O estudo de natureza investigativa foi realizado em três etapas, utilizando o documentário 'Evolução pela Alimentação', produzido em 2009 pelo canal Discovery Channel e disponível gratuitamente na Plataforma Youtube (DOCUMENTÁRIOS CIÊNCIA, 2013), como artefato pedagógico orientador na promoção dos debates em sala de aula. A temática central da produção audiovisual atrelou a evolução do Homo sapiens com seus hábitos alimentares e seu desenvolvimento narrativo abordou conceitos científicos ligados às Ciências Biológicas. 
Após a exibição dos 3 diferentes trechos do documentário, os estudantes participaram de grupos focais, guiados por questões orientadoras e registradas através de roteiro de observação específico. Em seguida, os estudantes respondiam a um questionário contendo questões objetivas e dissertativas, com perguntas desenvolvidas a partir do documentário apresentado e dos conceitos biológicos presentes em sua narrativa. Os conceitos selecionados e inseridos nos questionários respeitavam os conteúdos programáticos trabalhados na disciplina de Biologia na $1^{\mathrm{a}}$ e $2^{\mathrm{a}}$ Série.

Os índices de acerto das questões objetivas foram apurados através de estatística simples (porcentagem) e comentados em seguida. Foi solicitado aos participantes que opinassem sobre o seu grau de segurança ao responderem cada uma das questões objetivas (muito seguro, seguro, neutro, inseguro e muito inseguro), com base nos princípios de verificação da Escala de Likert (LIKERT, 1932). No contexto das pesquisas sobre Educação, a escala tem como objetivo mensurar questões atitudinais (CAZORLA; SILVA JUNIOR; SANTANA, 2018), apresentando uma variável possível de comparação nas diferentes etapas da atividade.

Os resultados qualitativos, representados pelas respostas dissertativas dos estudantes, foram selecionados com base na sua representatividade, dentro do escopo total. Como referencial para a discussão das repostas dissertativas, utilizamos a definição dos conceitos apresentados pelos livros didáticos de Biologia utilizado pela escola (FAVARETTO, 2017) e de referências externas, provenientes de artigos.

\section{RESULTADOS E DISCUSSÃO}

Como resultado, obtivemos 20 questionários respondidos na primeira etapa da intervenção, 22 questionários na segunda e 23 na terceira etapa, resultando em 65 questionários analisados ao total. Os questionários de observação subsidiaram a presente pesquisa, com resultados pautados nas discussões e questionamentos levantados pelos estudantes durante todo o percurso da atividade.

\subsection{PRIMEIRA ETAPA DA INTERVENÇÃO}

Ao serem questionados sobre a Questão Central da intervenção "Como a alimentação interfere nos hábitos de vida dos seres vivos?", os estudantes utilizaram como argumento a necessidade de uma boa alimentação para a manutenção da saúde e evolução do ser humano, Recebido em: 02/02/2021 
sem apresentar outros elementos em suas respostas que discutissem sobre outros seres vivos ou as demais funções biológicas além da nutrição.

As respostas à $1^{\text {a }}$ Questão Orientadora "Quais elementos biológicos vocês conhecem que evidenciam que os seres vivos mudaram ao longo do tempo?”, foram construídas apenas reproduzindo elementos presentes no documentário, como mudança do tamanho das ossadas ou registro de figuras rupestres, sem que houvesse um aporte conceitual prévio suficiente para justificar seus argumentos. Chaves, Moraes e Lira-da-Silva (2018) discutem que a abordagem deficiente de conceitos relacionados às Ciências da Terra, como o Tempo Geológico, limita estudantes e professores na discussão de conteúdos relacionados à Evolução.

A $2^{\text {a }}$ Questão Orientadora "Nossa alimentação se diferencia das de outros animais?" levantou discussões acerca dos diferentes hábitos de alimentação dos seres vivos. Inicialmente, os estudantes identificaram a alimentação humana como variada, o que, segundo eles, não ocorria em outros animais. Porém, em seguida, eles começaram a identificar animais que também possuem diferentes fontes alimentares, mas sem discutir conceitos que envolvessem esses hábitos, como onivoria, herbivoria e autotrofia.

Ao discutirem sobre a $3^{\text {a }}$ Questão Orientadora "Existem vantagens nessa diferença?", esperava-se que os estudantes refutassem a ideia inicial de "vantagens" dentro de questões evolutivas na Biologia, o que não ocorreu. Foi consenso entre os estudantes, que no caso dos humanos, uma fonte variada de alimentação oferece mais vitaminas para o corpo.

O questionário trouxe como primeira pergunta objetiva a definição do conceito de evolução biológica: "Quais dessas frases você acredita se aproximar mais do conceito de evolução?". Como resposta, 65\% $(\mathrm{n}=13)$ dos estudantes responderam a alternativa indicada como correta "É a mudança das características hereditárias de uma população de seres vivos de uma geração para outra" de acordo com Favaretto (2017) e Araguaia (2019), sendo 84\% $(n=9)$ responderam estar muito seguros ou seguros de suas respostas e 16\% $(n=02)$ optando pela neutralidade. A escolha dessa alternativa indica que o estudante consegue elaborar uma lógica relacionando conceitos de genética ao conceito de evolução, compreendendo o processo evolutivo como contínuo e transmitido ao longo das gerações.

Em complemento, dos 25\% $(n=5)$ que escolheram alternativas incorretas, $80 \%(n=4)$ optaram pela neutralidade e $20 \%(\mathrm{n}=1)$ responderam que estavam muito seguros. As alternativas escolhidas foram "Habilidades desenvolvidas apenas pelos seres humanos para a

Recebido em: 02/02/2021

Aceite em: 14/06/2021 
sobrevivência na terra" e "É a mudança de comportamento dos animais e plantas com finalidade de comer diferentes alimentos". Acredita-se que as escolhas dessas alternativas estejam relacionadas a não compreensão da evolução como um processo que envolve todas as formas de vida, enxergando apenas os seres humanos como passivos da evolução, ignorando fatores como genética e hereditariedade. Um total de $10 \%(\mathrm{n}=02)$ dos estudantes tiveram suas respostas consideradas não válidas, ou seja, respostas marcadas de maneira dúbia.

A segunda questão objetiva do questionário trazia um questionamento sobre o conceito de Cadeias Tróficas: "Durante a primeira parte do documentário 'Evolução Pela Alimentação', o narrador diz a seguinte frase: 'As plantas captam a energia do Sol para crescer, e os animais comem as plantas'. De acordo com os seus conhecimentos, essa frase pode ser traduzida em:”. De forma geral, $80 \%(n=16)$ dos estudantes optou pela alternativa correta "Existem diferentes níveis de cadeia alimentar, onde as plantas estão na base, seguido pelos animais que se alimentam de plantas e depois pelos animais animas que se alimentam de carne, formando uma cadeia alimentar" de acordo com as definições de Cassini (2005) e Favaretto (2017).

Desses estudantes, 63\% $(n=10)$ responderam estar muito seguros ou seguros e $37 \%$ $(\mathrm{n}=06)$ optou pela neutralidade. Apenas $5 \%(\mathrm{n}=1)$ dos estudantes assinalaram a alternativa incorreta "Plantas são seres vivos inferiores, pois só se alimenta da luz do sol, e por isso é menos importante do que outros seres vivos na natureza, que são mais complexos", informando estar seguro de sua resposta. A escolha dessa alternativa sugere que o estudante classifique os seres vivos em grau de importância de acordo com sua fonte alimentar, colocando os carnívoros, por exemplo, como seres mais complexos. Os $15 \%(n=3)$ dos estudantes restantes tiveram respostas consideradas não válidas.

Em seguida, os estudantes responderam as questões dissertativas. Ao serem questionados sobre o conceito de Vitaminas, os estudantes responderem que:

Estudante B.C.P: As vitaminas ajudam a prevenir doenças e nos deixa mais imunes; Estudante S.M.O.C: Manter nossos corpos com bons funcionamentos;

Estudante N.C.O: Agem na coloração da nossa pele, na formação dos nossos ossos, no funcionamento do nosso cérebro, e na manutenção do nosso sangue.

De maneira geral, as respostas dos estudantes foram direcionadas a importância das vitaminas para a saúde, funcionamento e manutenção das funções vitais. Apenas o estudante 
N.C.O nominou partes específicas e diferentes funções, ainda que sua resposta se limite a função biológica de um ponto de vista do senso comum.

Em seguida, solicitados a responder sobre o conceito de Genealogia, através da explicação sobre Árvore Genealógica, os estudantes apontaram que:

Estudante K.C.S.C: Árvore genealógica é um desenho para representar nossos ancestrais;

Estudante A.M.D: Árvore genealógica é quando montamos uma árvore com fotos dos nossos parentes e descobrimos nossos parentes distantes;

Estudante T.S.N: Podem estabelecer com mais cuidado a relação entre os seres vivos através de características evolutivas.

Acredita-se que os participantes basearam sua resposta a partir das representações como a árvore genealógica presentes no seu percurso formativo, que parte dos esquemas de representação familiar comum às fases iniciais da educação, mas que não são capazes de contemplar as questões biológicas como ancestralidade, descendência e origem. A maioria das repostas dadas pelos estudantes, limitou-se a citações sobre a ancestralidade humana, exceto pelo estudante T.S.N que utilizou os termos "seres vivos" para contemplar a sua ideia de que o estabelecimento de relações e sua representação se estende a outras formas de vida.

\subsection{SEGUNDA ETAPA DA INTERVENÇÃO}

Quando questionados sobre a Questão Central desta intervenção "De que maneira o comportamento do ser humano impactou e impacta na natureza?", os estudantes discutiram pontos ligados aos impactos ambientais causados pelo homem nas áreas urbanas, o incorreto descarte de lixo e a poluição atmosférica. Ainda que esses pontos sejam relevantes, os estudantes não embasaram as suas justificativas com conceitos científicos, mesmo estimulados a isso pelos pesquisadores nas discussões.

A $1^{\text {a }}$ Questão Orientadora tratou do modo como o ser humano se relaciona com a natureza e de como essa relação pode se desenvolver de maneira harmônica. Os participantes retomaram o argumento anterior que tratava da produção do lixo e indicaram caminhos para que isso pudesse acontecer, como a reciclagem, a reutilização de matérias de origem plásticas, além da utilização de material de origem vegetal e biodegradável na substituição de sacolas plásticas para compras em supermercados.

Como $2^{\mathrm{a}}$ Questão Orientadora, os estudantes foram questionados do modo de utilização dos recursos naturais pelo ser humano durante seu processo evolutivo. Em suma, os Recebido em: 02/02/2021

Aceite em: 14/06/2021 
estudantes utilizaram a evolução tecnológica como a pauta escolhida para direcionar o debate, através do surgimento de aparatos para a conservação do alimento, processamento e produção em massa. Ao falarem sobre transgênicos, mesmo sem citações a Biotecnologia, os estudantes indagaram sobre os efeitos de alimentos geneticamente modificados, avançando nas discussões ao incrementar elementos que ultrapassam conceitos imbricados na Biologia.

Ainda na direção da relação do ser humano e da natureza na perspectiva biológica, a $3^{\mathrm{a}}$ Questão Orientadora tinha como objetivo discutir as diferenças entre organismos vivos atualmente com seus ancestrais. Os estudantes apresentaram outro salto nas discussões, ainda que sem discutir profundamente sobre conceitos genéticos, os discentes apresentaram argumentos que sustentavam a ideia de que as modificações ocorridas em gerações anteriores se perpetuavam pelas novas gerações, ao passo que algumas eram perdidas.

Em seguida, sobre o conceito de domesticação, os estudantes responderam a seguinte pergunta: De acordo com seus conhecimentos, qual desses conceitos é o mais correto do ponto de vista biológico acerca da domesticação?”. Sobre esse questionamento, 68\% (n=15) dos estudantes optaram pela escolha da alternativa “domesticação é um processo histórico e biológico, onde plantas e animais passaram por sucessivas adaptações artificialmente, para desempenhar as mais diversas funções, entre elas a alimentação", segundo Clutton-Brock (1999). Sobre seu grau de segurança $94 \%(n=14)$, informaram estar muito seguro ou seguro, frente $6 \%(n=1)$ que optou pela neutralidade. A escolha dessa alternativa sugere que o estudante consegue compreender a domesticação como um processo histórico e adaptativo.

Os demais $23 \%(n=5)$ responderam uma alternativa incorreta que afirmava que a "domesticação é o processo de tornar o animal mais dócil e carinhoso, para que ele possa conviver com o ser humano e outros animais de maneira pacífica", sendo $100 \%(\mathrm{n}=5)$ afirmando estar muito seguro ou seguro de sua resposta. A escolha desta alternativa sugere que o estudante compreende a domesticação como um processo de docilização de animais com o objetivo de conviver com o ser humano, ainda que exercendo diferentes funções. Apenas $9 \%(\mathrm{n}=2)$ tiveram respostas não válidas.

Duas questões dissertativas estiveram presentes nesta etapa da intervenção. Os estudantes responderam sobre os conceitos de Mutação Gênica e Energia do ponto de vista da Biologia. Primeiramente, eles responderam a seguinte pergunta o que é mutação? Por que a mutação dá origem a novas espécies?":

Recebido em: 02/02/2021

Aceite em: 14/06/2021 
Estudante F.M: "Mutação é a mistura de duas espécies dando origem a uma nova espécie";

Estudante S.J.A.G: Mutação é um processo de evolução que muda as características genéticas;

Estudante B.S: É a mudança de características que cria uma nova espécie;

Estudante L.G: A mutação é a mudança do DNA do indivíduo.

Quando perguntados sobre o conceito de mutação, os estudantes constroem a definição conceitual atrelando as mudanças de características como resultantes de mudanças no organismo do indivíduo, citando a origem de novas espécies e de características genéticas. Porém, tais afirmativas não são acompanhadas de dados, apenas de percepções conceituais que se interligam sem que haja uma sequência clara.

Em seguida, dissertaram sobre o conceito biológico de energia. "Para a física, Energia é a capacidade de um corpo gerar trabalho. Para a Química, Energia é a capacidade química que um corpo tem para produzir um efeito. De acordo com os seus conhecimentos, o que seria a Energia para a Biologia?".

Estudante J.L.O: Energia na Biologia trata-se da alimentação, pois quando a pessoa está com fome ela não consegue fazer esforço físico;

Estudante S.F.J: Força que mantém nosso corpo ativo, quando consumimos o necessário, quando não, nosso corpo fica fraco;

Estudante G.R: Na minha opinião, é a capacidade do ser humano em transformar alimento em combustível para gerar energia para o corpo.

Quando perguntados sobre o conceito de energia do ponto de vista biológico, os discentes de maneira geral, não conseguiram se aproximar satisfatoriamente do conceito de energia. Foi possível perceber que os estudantes recorreram ao tema do documentário, que tem a alimentação como eixo orientador, para construir suas respostas, limitando suas afirmações sobre a energia como resultado da alimentação.

\subsection{TERCEIRA ETAPA DA INTERVENÇÃO}

Questionados sobre os hábitos alimentares dos seres humanos atualmente e sobre a qualidade desta alimentação, a questão central desta etapa, "Podemos dizer que nós somos o que comemos?", buscou a abertura do diálogo sobre o consumo elevado de alimentos industrializados e com conservantes. Os estudantes trouxeram argumentos pessoais sobre a sua alimentação, reconhecendo que consomem de maneira excessiva alimentos processados em suas refeições, mesmo tendo conhecimento dos prejuízos à saúde. É interessante de como paulatinamente os estudantes vão se familiarizando com a atividade, e passam a realizar de

Recebido em: 02/02/2021

Aceite em: 14/06/2021 
maneira mais confortável reflexões acerca do assunto abordado, traçando relações com seus comportamentos e ações enquanto indivíduos.

Seguindo a mesma direção, a $1^{\text {a }}$ Questão Orientadora questionou sobre o uso da tecnologia na produção de alimentos e suas consequências: "As novas tecnologias ajudam ou prejudicam a qualidade do que nós comemos?". Os estudantes continuaram o debate sobre como a alimentação é produzida pelas grandes indústrias, com o uso de conservantes, mas refletindo sobre a necessidade de uma produção em larga escala para atender a toda humanidade. Ainda que sem aprofundamento da questão foi consenso que, tomando como base a alimentação de seus pais e avós, a utilização de alimentos classificados como prejudiciais aumentaram consideravelmente como fruto da industrialização, que segundo eles, é fruto do desenvolvimento tecnológico.

Em seguida, a $2^{\text {a }}$ Questão Orientadora trouxe para o centro do debate doenças que surgem em decorrências de fatores alimentares. Com a pergunta "Como surgem às doenças relacionadas à alimentação no organismo humano?” os estudantes exemplificaram doenças crônicas como diabetes, hipertensão e neoplasias mais conhecidas, mas restringiram a sua argumentação ao relato das consequências, sem que houvesse um desenvolvimento do argumento a partir de processos biológicos.

Por fim, ao direcionar o momento de livre debate perante questões explicitamente ligadas ao meio ambiente, os estudantes foram perguntados se "o ser humano utiliza a natureza de maneira adequada para produzir o seu alimento?". Partindo de um senso comum, ainda que carregado de elementos verdadeiros, os estudantes foram unanimes ao afirmar que o ser humano utiliza inadequadamente os recursos naturais para a produção de alimentos. Segundo os discentes, o desmatamento e a utilização de agrotóxicos, são os fatores que mais oneram o meio ambiente.

A única questão objetiva desta etapa, "De que natureza se refere o processo de fermentação da cerveja", tratou da situação apresentada no documentário quanto à descoberta da cerveja como produto da fermentação da cevada. Em síntese, $78 \%$ dos estudantes escolheram a alternativa correta "Fermentação alcoólica, promovida por leveduras, que resulta em álcool etílico" segundo Dias (2019) e Favaretto (2017). Desses estudantes, 84\% $(n=15)$ informaram estar muito seguros ou seguros de suas respostas, $11 \%(n=02)$ optaram pela neutralidade e $5 \%(\mathrm{n}=01)$ disse estar inseguro. A escolha dessa alternativa sugere que o estudante consegue identificar que os processos de fermentação têm diferentes especificidades, além de compreender a fermentação em questão como um processo biológico e seus resultados dentro do contexto solicitado.

Em acréscimo, os $22 \%$ que não marcaram uma das alternativas diferentes da indicada como corretas sendo elas "fermentação biológica, promovida por leveduras, que resulta em Recebido em: 02/02/2021 
água e gás carbônico" e "fermentação láctica, reduzindo o piruvato a lactato, resultando em ácido lático", sugerem que estes estudantes apesar de compreenderem diferentes processos de fermentação falharam ao contextualizar tais conceitos a situação proposta. Desses estudantes, $80 \%(n=4)$ informaram estar inseguros e $20 \%(n=1)$ apontaram estarem seguros.

Por fim, os estudantes passaram a se deparar com as questões dissertativas desta etapa. Além de exigir a definição conceitual de termos ligados à Biologia, os estudantes também deveriam exemplificar processos dos quais estavam dissertando. Como primeira questão, os estudantes deveriam explicar "o que é o metabolismo e qual a importância do seu perfeito funcionamento?":

Estudante L.G.R.P: É um conjunto de transformações de substancia que o organismo absorve, e é importante para o bom funcionamento e distribuição de energia para o corpo;

Estudante M.J.O: Conjunto de reações químicas que ocorrem na célula;

Estudante P.D.S: O metabolismo é sentido no corpo humano, que apresenta reações que ocorrem no nosso corpo.

Os estudantes demonstraram dificuldades ao conceituar metabolismo e processos metabólicos em sua argumentação, apesar de demonstrarem algum domínio sobre o conteúdo, mesmo que de forma superficial. A compreensão como conjunto de transformações ou reações químicas que resultam em matéria energética para o corpo também foi um modo de compreensão presente nas falas dos participantes.

Quando perguntados sobre "A síntese proteica é um processo que ocorre dentro das células. De acordo com seus conhecimentos, explique o porquê o mau funcionamento do processo de síntese seria prejudicial ao organismo humano" os estudantes responderam que:

Estudante L.D.S: É uma ‘dissolução’ de nutrientes, que com um mau funcionamento poderá trazer problemas ao nosso organismo;

Estudante P.D.R: A síntese é um processo quase que digestório, de nutrientes, sem ele o nosso corpo não recebe os nutrientes;

Estudante C.D.N: A síntese proteica nutre nossos órgãos nutrindo o organismo;

Estudante B.R: A síntese com mau funcionamento prejudica a saúde.

Esperava-se que os estudantes ao conceituar a síntese proteica trouxessem outros elementos como função do ribossomo, etapas de codificação do DNA, produção do RNA, entre outros. Porém, os estudantes limitaram-se a associar a síntese proteica como um processo ligado a nutrição e, por consequência, solicitados a explicar a importância do seu correto funcionamento, utilizaram a subnutrição como principal consequência.

\subsection{UMA VISÃO GLOBAL SOBRE OS RESULTADOS}

Recebido em: 02/02/2021

Aceite em: 14/06/2021 
Os roteiros de observação nos mostram que quando levantados questionamentos para discussão em grupo, os estudantes frequentemente basearam suas argumentações em elementos do senso comum. Ainda que fossem pertinentes as suas afirmativas, as discussões não se ampliaram para uma discussão orientada por questões científicas, mesmo quando estimulados pelos pesquisadores enquanto mediadores da atividade.

Após a exibição do trecho do documentário, os estudantes frequentemente utilizavam elementos vistos durante o mesmo para justificar seus argumentos. É interessante observar que, mesmo que direcionados a isso de maneira não intencional, os estudantes passaram a ancorar seus argumentos em uma fonte de informação (o documentário) que não àquelas vinculadas inicialmente ao senso comum, demonstrando como o audiovisual pode sim influenciar na formação de opiniões e reflexões discentes.

No que se refere às questões objetivas, percebeu-se resultados para uma análise de compreensão conceitual. Os estudantes apresentaram índices de acerto acima de $65 \%$, sendo os conceitos de Evolução e Domesticação com os menores índices de acertos $65 \%$ e $68 \%$ cada um, enquanto Cadeias Tróficas o maior com $80 \%$. Os pesquisadores perceberam que durante as discussões, antes mesmo da aplicação dos questionários, os estudantes estavam mais familiarizados com assuntos ligados a Ecologia do que Biologia Molecular, por exemplo. Escodino e Góes (2016) já afirmavam dificuldades cognitivos e na democratização do acesso a informações científicas no Brasil quanto à compreensão de conceitos da Biologia Molecular.

Soma-se aos resultados objetivos a escala de Likert (Figura 1). Em suma, foi possível perceber uma clara evolução dos estudantes quanto ao nível de segurança "Muito Seguro", saltando de $17 \%$ para $47 \%$ ao fim da última etapa de intervenção. Os estudantes que marcaram estar "Seguros" das suas respostas foram diminuindo de 52\% para $30 \%$ ao passo que os "Muito Seguros" foram alcançando novos picos. Se juntam a análise desses dados os estudantes que optaram pela "Neutralidade": de cerca de $30 \%$ na primeira etapa de para cerca de $8 \%$ na última. Acredita-se que esse resultado possa representar uma mudança de postura dos estudantes quanto à confiança quanto ao aporte teórico em questão e ao fato de assumir o seu posicionamento durante as intervenções.

Coube aos pesquisadores a construção gradativa durante as intervenções de um ambiente que não reproduzisse a atmosfera criada pelas avaliações rotineiras escolares nas quais eles estavam imersos. Outro dado revelado pela Escala de Likert foram dos estudantes 
que informaram estar "Inseguros" de suas respostas, de 2\% na primeira intervenção, para 13\% na última etapa. É importante ressaltar, que à medida que a atividade foi sendo realizada, mais estudantes foram aderindo à intervenção, o que pode representar um fator de influência no aumento dessa variável.

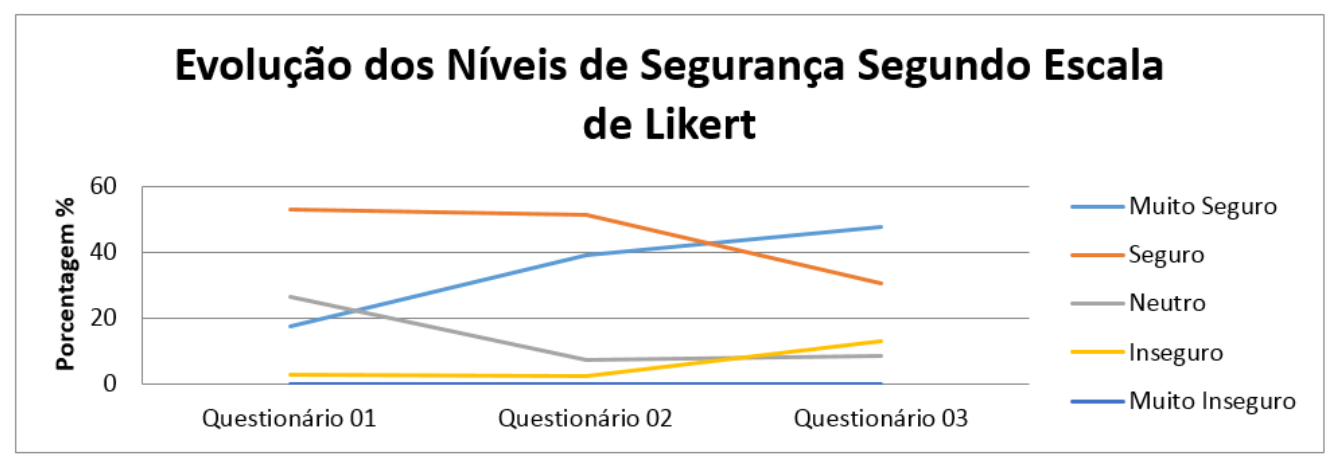

Figura 1 - Gráfico representa percentualmente a evolução dos níveis de segurança dos participantes a cada etapa de realização da intervenção. Fonte: Autores.

Quando observadas as questões dissertativas, os estudantes apresentaram dificuldades em nível de conceituação básica em suas respostas, não sendo capazes de construir narrativas sequenciais com conceito, dados e justificativas. Assim como destacado nos roteiros de observação, foi comum respostas elementares, principalmente na esfera das justificativas. Por fim, Del Pino e Strack (2012) criticam ainda o uso de estratégias formais da educação científica que deixam de lado fenômenos reais, mantendo os estudantes a um modelo avaliativo ultrapassado de perguntas e respostas.

\subsection{INTERFACES COM OS PRESSUPOSTOS DEFINIDOS PELO PISA}

Primeiramente, é necessário ressaltar que o presente trabalho não é capaz de contemplar todo o universo presente nas avaliações sobre o LC assim como as avaliações oficialmente reconhecidas como do Instituto Brasileiro de Letramento Científico (ILC) e os do Programa Internacional de Avaliação de alunos (PISA). Será utilizado nesse momento, as inter-relações do PISA entre as dimensões do LC como base para discutir esta etapa dos resultados a partir da esfera da compreensão conceitual.

O PISA define que a demonstração das competências definidas pelo programa sendo elas a: 1) explicação de fenômenos cientificamente, 2) avaliação e planejamento de experimentos e 3) interpretação dos dados e evidências cientificamente, dependem do próprio arcabouço teórico dos estudantes dos conteúdos de Ciências (Figura 2).

Recebido em: 02/02/2021

Aceite em: 14/06/2021 


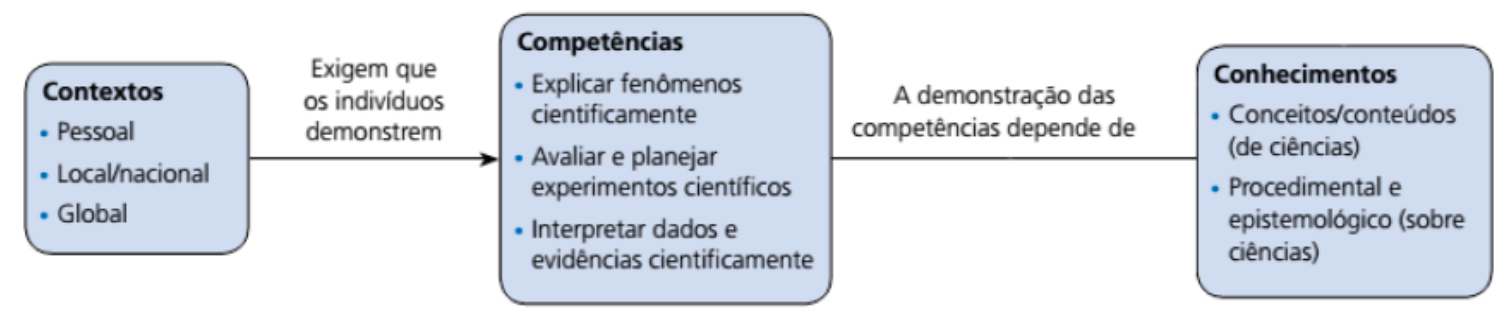

Figura 2 - Dimensão das inter-relações do Letramento Científico definido pelo Programa Internacional de Avaliação de Estudantes. Fonte: BRASIL (2018).

Os resultados apresentados até aqui, nos mostram a grande lacuna da compreensão de conceitos e conteúdos pelos sujeitos de pesquisa. Logo, o desenvolvimento das competências exigidas é comprometido. Com base nas informações produzidas, passemos, de forma sucinta, a recapitular alguns exemplos:

Estudante A.M.D: Árvore genealógica é quando montamos uma árvore com fotos dos nossos parentes e descobrimos nossos parentes distantes.

A compreensão sobre o conceito de Genealogia é superficial. Existe uma clara deficiência de apropriação do conteúdo presente dentro abordagens sobre Genética e Evolução. O estudante então utiliza dados da sua experiência pessoal para ilustrar o que está explicando, através de uma representação genealógica sem aporte científico.

Estudante G.R: Na minha opinião, [energia] é a capacidade do ser humano em transformar alimento em combustível para gerar energia para o corpo.

Este estudante inicia o seu embasamento justificando que sua resposta é baseada em sua opinião, excluindo o conteúdo baseado nos conceitos científicos. A superficialidade na explicação baseada no senso comum não fornece dados consistentes para uma argumentação suficiente para a explicação do fenômeno científico em questão.

Em suma, como podem os estudantes desenvolver satisfatoriamente as competências definidas pelos PISA, sem sequer compreenderem conceitos científicos, nesses casos, básicos das Ciências Biológicas e compatíveis com a sua idade e série escolar? Os estudantes, portanto, não apresentaram resultados esperados nem durante as discussões nem em suas respostas dissertativas que representassem tomadas de decisões, reconhecimento de decisões implícitas no cotidiano, uma argumentação concisa, baseada em elementos científicos e levantamento de hipóteses, concordando assim com os resultados apresentados no estudo realizado por Lima e Weber (2019). 
Outro ponto de discussão estudado se refere aos conceitos científicos presentes nas Ciências Biológicas. Além das percepções dos pesquisadores sobre a dificuldade da compreensão desses termos no contexto escolar, também já foram identificadas reflexões mais globais discutidas na literatura (MAYER et al., 2015; SOUZA et al., 2018; DELIZOICOV; ANGOTTI; PERNAMBUCO, 2018; DURÉ; ANDRADE; ABÍLIO, 2018), quanto aos desafios dos conceitos científicos presentes na Biologia pela sua riqueza de terminologias, diversidade e alto grau de abstração.

As dificuldades discutidas por esses autores citados dialogam com os resultados apresentados no presente trabalho. Tais dados somam-se aos achados desses autores ao aglutinar à ótica do LC e de seus desafios às dificuldades presentes na compreensão de termos científicos ligados as Ciências Biológicas, dentro do contexto escolar de estudantes de uma Escola Pública localizada na cidade de Salvador, Bahia (Brasil).

\section{CONSIDERAÇÕES FINAIS}

Como conclusão deste trabalho, percebemos que estudantes do terceiro ano do Ensino Médio de uma escola pública de Salvador apresentam substanciais deficiências na compressão de termos científicos ligados as Ciências Biológicas, e como essas deficiências culminam na evidente dificuldade de embasar seus argumentos e reflexões a partir dos conceitos científicos, um dos principais pressupostos do Letramento Científico. Tal resultado expõe fragilidades presentes no Ensino de Ciências, com ênfase no Ensino de Biologia, ainda que as premissas do LC estejam presentes nos documentos da Educação Básica, como a BNCC.

Avanços no que se refere aos dispositivos curriculares se fazem necessários para que princípios balizados no LC possam ser considerados em meio ao próprio Ensino de Ciências. Historicamente, essa grande área do saber no Brasil vem se caracterizando pela valorização do aprendizado de conceitos, com estratégias mecânicas e rotineiras e que pouco contribui para a formação cidadã dos sujeitos. A aquisição do sentido mais amplo de palavras auxilia na elucidação do significado de novos conceitos, patamar dificilmente alcançado atualmente.

Muitas tem sido as críticas em relação ao padrão de avalição das instituições em relação ao LC, como o próprio PISA, um dos parâmetros utilizados na discussão dos resultados deste artigo. Na literatura há críticas de que os parâmetros utilizados pelo PISA não levam em conta questões regionais e balizam suas avaliações apenas em métricas técnicas. O âmbito da 
realização deste trabalho possibilitou a reflexão desses parâmetros com uma maior proximidade da realidade escolar local.

De uma forma ou de outra, as avaliações de Letramento Científico demonstram que a educação científica não vem trilhando um caminho efetivo, mesmo em alguns países com elevado grau de escolarização de sua população, atrelando ou não aos objetivos práticos, valores meramente científicos ou vinculado a aportes socioculturais. Por fim, espera-se que este artigo possa subsidiar futuros trabalhos pautados nos contextos aqui abordados que entrelacem os campos do Ensino de Ciências e do LC.

\section{REFERÊNCIAS}

ALBUQUERQUE, Gabriela; BRAGA, Rodrigo; GOMES, Vinicius. Conhecimento dos alunos sobre microrganismos e seu uso no cotidiano. Revista de Educação, Ciências e Matemática, v. 2, n. 1, 2012.

ARAGUAIA, Mariana. "Evolução"; Brasil Escola. Disponível em: https://brasilescola.uol.com.br/biologia/evolucao.htm. Acesso em 30 de maio de 2019

ARAÚJO, Maria; BARROS, Gleize; BARROS, Marcos. A Construção da Identidade Docente do Licenciado de Ciências Biológicas em Início de Carreira. Revista Insignare Scientia, v. 1, n. 2, 2018.

BAHIA. Consulta Escola: CEMAB. Secretaria da Educação. 2019. Disponível em http://escolas.educacao.ba.gov.br/node/11994. Acesso em 10 de Janeiro de 2020

BRANCO, Alessandra et al. alfabetização e letramento científico na bncc e os desafios para uma educação científica e tecnológica. Revista Valore, v. 3, p. 702-713, 2018.

BRANCO, Emerson; ZANATTA, Shalimar. BNCC e Reforma do Ensino Médio: implicações no ensino de Ciências e na formação do professor. Revista Insignare Scientia, v. 4, n. 3, p. 58-77, 2021.

BRASIL. INEP. Resumo Técnico: resultado do índice de desenvolvimento da educação básica. Brasília, MEC/INEP, 2017.

BRASIL. Base Nacional Comum Curricular - BNCC. Instituto Nacional de Pesquisas Educacionais Anísio Teixeira. Brasília, MEC, 2018.

BRASIL. Instituto Nacional de Estudos e Pesquisas Educacionais. Programa Internacional de Avaliação dos Estudantes (PISA). Relatório Brasil no PISA 2018. Brasília: MEC/INEP. 2019.

CASSINI, Sérgio. Ecologia: conceitos fundamentais. Espírito Santo: EDUFES, 2005.

Recebido em: 02/02/2021

Aceite em: 14/06/2021 
CAZORLA, Irene; SILVA JÚNIOR, Antônio; SANTANA, Eurivalda. Reflexões sobre o ensino de variáveis conceituais na educação básica. Revista de Ensino de Ciências e Matemática, v. 9, n. 2, p. 354-373, 2018.

CHAVES, Rafaela; MORAES, Simone; LIRA-DA-SILVA, Rejâne. Por que ensinar tempo geológico na educação básica?. Terræ Didatica, v. 14, n. 3, p. 233-244, 2018

CLUTTON-BROCK, Juliet. A natural history of domesticated mammals. Cambridge: Cambridge University Press, 1999.

DEL PINO, José; STRACK, Ricardo. O desafio da cientificidade na sala de aula. Revista Pátio Ensino Médio. V. 12, n.01, 2012, p. 11-13.

DELIZOICOV, Demétrio; ANGOTTI, José; PERNAMBUCO, Marta. Ensino de Ciências: fundamentos e métodos. São Paulo: Cortês, 2018.

DIAS, Diogo. "O que é fermentação?". Brasil Escola. 2019. Disponível em: https://brasilescola.uol.com.br/o-que-e/quimica/o-que-e-fermentacao.htm. Acesso em $22 \mathrm{de}$ janeiro de 2021.

DOCUMENTÁRIOS CIÊNCIA. Evolução pela Alimentação. Youtube, 22 de set. de 2013. Disponível em https://youtu.be/6jvWAAhGs44.

DURÉ, Ravi; ANDRADE, Maria; ABÍLIO, Francisco. Ensino de biologia e contextualização do conteúdo: quais temas o aluno de ensino médio relaciona com o seu cotidiano.

Experiências em ensino de ciências, v. 13, n. 1, p. 259-272, 2018.

ESCODINO, Daniel; GÓES, Andréa. Alfabetização científica e aprendizagem significativa: situação de alunos de escolas estaduais do Rio de Janeiro com relação a conceitos de biologia molecular. Investigações em Ensino de Ciências, v. 18, n. 3, p. 563-579, 2016.

FAVARETTO, José. $\mathbf{3 6 0}^{\circ}$ - Biologia: Unidade e Diversidade (Volume 1). São Paulo: FTD Educação, 2017.

INSTITUTO ABRAMUNDO. Indicador de Letramento Científico: relatório técnico da edição 2014. São Paulo, SP, 2014.

KRASILCHIK, Myriam; MARANDINO, Martha. Ensino de ciências e cidadania. São Paulo: Editora Moderna, 2004.

LIKERT, Rensis. A technique for the measurement of attitudes. Archives of psychology, 1932.

LIMA, Mikeas; WEBER, Karen. Determinação de níveis de letramento científico a partir da resolução de casos investigativos envolvendo questões sociocientíficas. Educación química, v. 30 , n. 1 , p. $69-79,2019$ 
LORENZETTI, Leonir; DELIZOICOV, Demétrio. Alfabetização científica no contexto das séries iniciais. Tese de Doutorado. Universidade Federal de Santa Catarina, Centro de Ciências da Educação, 2001.

MAYER, Margareth et al. Professor: mediador entre o abstrato e o concreto. In: Encontro Nacional de Pesquisa em Educação em Ciências (ENPEC), Anais... Atibaia, v. 3, p. 1-6, 2001.

SANTOS, Wildson. Educação científica na perspectiva de letramento como prática social: funções, princípios e desafios. Revista brasileira de educação, v. 12, n. 36, p. 474-492, 2007.

SERRAO, Luis et al. A experiência de um indicador de letramento científico. Cadernos de Pesquisa, v. 46, n. 160, p. 334-361, 2016.

SOARES, Magda. Alfabetização e letramento: caminhos e descaminhos. Revista Pátio, v. 29, p. 19-22, 2004.

SOUZA, Tadeu et al. Letramento científico na docência de professores de biologia: concepção e prática. REAMEC - Rede Amazônica de Educação em Ciências e Matemática, v. 6, n. 2, p. 310-323, 2018. 